\title{
Health MDGs: what has been achieved for maternal and child health in the Eastern Mediterranean Region?
}

\author{
Haifa Madi ${ }^{1}$
}

Fifteen years have passed since 189 heads of state signed the United $\mathrm{Na}$ tions (UN) Millennium Declaration in 2000, which placed emphasis on an integrated global agenda for poverty reduction, health, education and human development and included eight Millennium Development Goals (MDGs) to be met by all the countries by the end of 2015 .

The focus of MDG 4 was reducing child mortality and that of MDG 5 was improving maternal health. With the time almost up, it is worth reviewing what progress the countries of the Eastern Mediterranean Region (EMR) have made towards reaching the targets set in these MDGs. Eight of the EMR countries have achieved the targets for child survival (MDG 4) and three have achieved the targets for maternal survival (MDG 5). Six countries have reduced maternal mortality ratio to less than 20 maternal deaths per 100000 live births and seven have reduced their under-five mortality to equal or less than 25 per 1000 live births $(1,2)$.

To improve maternal and child health in the Region, particularly in high burden countries sharing $95 \%$ of maternal and child deaths at the regional level, a regional initiative was jointly launched by WHO, UNFPA and UNICEF with Member States at a high-level meeting held in Dubai, United Arab Emirates, in January 2013. The meeting concluded with the Dubai Declaration: Saving the lives of mothers and children: rising to the challenge (2).
The Declaration was endorsed by the 60th session of the WHO Regional Committee for the Eastern Mediterranean in October 2013 in resolution EM/RC60/R.6. In the resolution, the Committee called on Member States with a high burden of maternal and child mortality (Afghanistan, Djibouti, Egypt, Iraq, Morocco, Pakistan, Somalia, Sudan and Yemen) to strengthen multisectoral partnership in order to implement their national acceleration plans, allocate national human and financial resources and work on mobilizing additional resources from donors, partners and development agencies.

Member States demonstrated their high commitment while developing the maternal and child health acceleration plans. Between June and November 2013, the nine Member States with a high burden of maternal and child mortality were able to finalize their plans. The plans were both integrated and comprehensive and targeted disadvantaged populations with a high burden of maternal and under-5 mortality with an emphasis on the main causes of maternal deaths (bleeding, sepsis and eclampsia) (3)and child deaths (diarrhoea, pneumonia and malnutrition) (4). Neonatal health care interventions were prioritized as neonatal mortality contributed to $46 \%$ of child mortality, mainly due to birth asphyxia, preterm birth complications and sepsis (5). Strengthening health systems in implementing the maternal and child health $(\mathrm{MCH})$ acceleration plans received special attention from the nine eligible Member States, in particular the availability of human resources for maternal and child health services and availability of life-saving medicines and equipment.

Country accountability frameworks were developed by stakeholders in the public health sector to translate the 10 recommendations of the Commission on Information and Accountability, including maternal death surveillance and response, civil registration and vital statistics, e-Health/innovation and advocacy, into practical steps for implementation (6).

By January 2014, all high burden countries were implementing the priority activities of the plans using locally available resources, the $\mathrm{WHO}$ start-up funds of US\$2 600000 and the WHO/ country collaborative programme for 2014-2015 totalling US\$ 7000000. All the funds were aligned with the acceleration plans and the overall implementation rate of the WHO start-up funds reached 99\% (7).

An intercountry meeting for national maternal, neonatal and child health programme managers was held jointly by WHO/UNFPA/UNICEF in 2015 to address main causes of maternal, neonatal and child mortality in the Region. The participating countries identified priority actions for facilitating the implementation of $\mathrm{MCH}$ acceleration plans in 2015 and strategic directions for reproductive, maternal, neonatal and child health programmes in the post-2015 agenda. 
To further improve maternal and child health outcomes in the Region, the Regional Office held a meeting in 2015 on preconception care to review and adapt a preconception care framework and core interventions using cost-effective, feasible and culturally sensitive interventions in the Region (8). A follow-up preconception care working group met in September 2015 to finalize the regional preconception care core interventions and underline the steps required for country programme development.

Maternal and child health remain a priority in the post-2015 agenda for the Region. Thirteen Member States have started to develop their reproductive, maternal, newborn, child and adolescent health (RMNCAH) strategic directions and priority actions in line with the 2015 global strategy for Women's, Children's and Adolescents' Health which was launched at the UN General Assembly in September 2015 (9).

Clearly there is much work ahead if we are to collectively improve maternal and child health and the wellness of the mothers and babies in the Region. Leadership, commitment, cooperation and involvement of all stakeholders and partners are essential to build on the progress so far and further the gains made in maternal and child health.

\section{References}

1. UNICEF, WHO, The World Bank, United Nations Population Division. Levels \& trends in child mortality. Report 2015. Estimates developed by the UN Inter-agency Group for Child Mortality Estimation. New York: United Nations Children's Fund; 2015

2. Summary report on the High-level meeting on saving the lives of mothers and children: rising to the challenge in the Eastern Mediterranean Region. Dubai, United Arab Emirates, 29-30 January 2013. Cairo: WHO Regional Office for the Eastern Mediterranean; 2013 ( WHO-EM/WRH/091/E) (http://applications.emro.who.int/docs/IC_Meet_Rep_2013_EN_14862. pdf, accessed 9 November 2015)

3. Lozano R, Naghavi M, Foreman K, Lim S, Shibuya K, Aboyans $\mathrm{V}$, et al. Global and regional mortality from 235 causes of death for 20 age groups in 1990 and 2010: a systematic analysis for the Global Burden of Disease Study 2010. Lancet. 2012 Dec 15;380(9859):2095-128. doi: 10.1016/S0140-6736(12)61728-0. PMID: 23245604

4. Black RE, Cousens S, Johnson HL, Lawn JE, Rudan I, Bassani DG, et al Global, regional, and national causes of child mortality in 2008: a systematic analysis. Lancet. 2010 Jun 5;375(9730):1969-87. doi: 10.1016/S0140-6736(10)60549-1. PMID: 20466419
5. Every Newborn: An Executive Summary for The Lancet's Series. Lancet. 2014 May.

6. Accountability for women's and children's health: report on progress to May 2014. Geneva: World Health Organization; 2014 (http://www.who.int/woman_child_accountability/ about/COIA_report_2014.pdf, accessed 9 November 2015).

7. Progress report on saving the lives of mothers and children. Sixty-first session of the WHO Regional Committee for the Eastern Mediterranean, 2014 (EM/RC61/INF.DOC.5) (http://applications.emro.who.int/docs/RC_technical_papers_2014_info_doc_5_15424_EN.pdf?ua=1, accessed 9 November 2015).

8. Summary report on the Meeting on promoting preconception care in the Eastern Mediterranean Region. Muscat, Oman. 2527 March 2015. Cairo: WHO Regional Office for the Eastern Mediterranean; 2013 (WHO-EM/WRH/096/E) (http://applications.emro.who.int/docs/IC_Meet_Rep_2015_EN_16333. pdf, accessed 9 November 2015).

9. Every woman, every child. The Global strategy for women's, children's and adolescent's health. Survive, Thrive, Transform. New York: United Nations; 2015 (http://who.int/ life-course/partners/global-strategy/globalstrategyreport2016-2030-lowres.pdf, accessed 9 November 2015). 